\title{
Marker Of Sepsis Severity Is Associated With The Variation In Cardio-Ankle Vascular Index (CAVI) During Sepsis Treatment
}

This article was published in the following Dove Press journal: Vascular Health and Risk Management

\author{
Daiji Nagayama ${ }^{1, *}$ \\ Haruki Imamura ${ }^{2} *$ \\ Kei Endo ${ }^{3}$ \\ Atsuhito Saiki ${ }^{2}$ \\ Yuta Sato ${ }^{2}$ \\ Takashi Yamaguchi ${ }^{2}$ \\ Yasuhiro Watanabe ${ }^{2}$ \\ Masahiro Ohira $\mathbb{D D}^{2}$ \\ Kohji Shirai ${ }^{4}$ \\ Ichiro Tatsuno $\mathbb{D i D}^{2}$ \\ 'Nagayama Clinic, Tochigi, Japan; ${ }^{2}$ Center \\ of Diabetes, Endocrinology and \\ Metabolism, Toho University, Sakura \\ Medical Center, Chiba, Japan; ${ }^{3}$ Endo \\ Clinic, Chiba, Japan; ${ }^{4}$ Department of \\ Internal Medicine, Mihama Hospital, \\ Chiba, Japan \\ *These authors contributed equally to \\ this work
}

Correspondence: Daiji Nagayama

Nagayama Clinic, 2-I2-22, Tenjin-Cho,

Oyama-City, Tochigi 323-0032, Japan

Tel +8I-285-22-0219

Fax +8I-285-22-0219

Email deverlast9607I@gmail.com
Introduction: The main pathophysiology of sepsis is considered to be circulation crisis with an imbalance of vasodilation and vasoconstriction mechanisms, which contributes to multiple organ failure. However, sepsis-induced hemodynamic changes have not been fully validated by novel arterial stiffness parameter. The aim of this study was to clarify the acute vascular alteration and hemodynamic change in sepsis using cardio-ankle-vascular index (CAVI).

Methods: Twenty-one Japanese patients (14 males and 7 females, age $62.8 \pm 19.0$ years) with sepsis were recruited. CAVI was measured before and 1-week after sepsis treatment.

Results: The leading underlying cause of sepsis was pyelonephritis, followed by pneumonia, lung abscess, hepatic abscess and cholecystitis. All subjects recovered from sepsis. Analysis of all subjects showed a significant increase in CAVI after 1-week treatment ( $7.9 \pm 2.4$ to $9.6 \pm 1.8$, $P<0.001$ ), but no significant change in blood pressure (BP) was observed. Significant correlations were observed for all combinations among the change in CAVI, systolic BP and ln [procalcitonin (PCT)], respectively. Additionally, in subjects with PCT at presentation $\geq 2.0 \mathrm{ng}$ / $\mathrm{mL}$, the increase in CAVI after treatment was significantly greater compared to those with PCT $<$ $2.0 \mathrm{ng} / \mathrm{mL}(2.4 \pm 1.6$ vs $1.1 \pm 0.9, P=0.037)$.

Discussion: CAVI may reflect sepsis-induced vascular alteration which is not indicated by BP change, and is associated with sepsis severity. These findings suggest the usefulness of CAVI in the management of circulatory failure in sepsis patients.

Keywords: SIRS, circulation crisis, procalcitonin, arterial stiffness

\section{Introduction}

Critically ill septic patients are prone to develop multiple organ failure with high mortality. Sepsis develops as a result of systemic inflammatory response syndrome (SIRS) to infection. Furthermore, the pathophysiologic features of sepsis result from the comprehensive effects of microbes and their products. ${ }^{1}$ These products can activate cytokines, complement, the coagulation system, plasmakinin, endorphins and the sympathetic nervous system. Recently, procalcitonin (PCT), a 116-amino acid-long precursor of calcitonin, has been proposed as a marker of infection, and serum PCT level positively correlates with the severity of infection. The major benefit of PCTguided therapy is a shorter duration of antibiotic treatment compared to standard care. ${ }^{2}$

Disseminated intravascular coagulation (DIC) is a principal complication of sepsis and characterized by massive thrombin formation and widespread microvascular thrombosis involved in multiple organ ischemia. ${ }^{3}$ Indeed, the pathophysiology of 
sepsis-induced circulatory failure includes not only coagulation disorders but also decreased blood flow. This hemodynamic change involves some degree of hypovolemia and a decrease in vascular tone. ${ }^{4}$ Vasodilation and vascular permeability induced by pro- and anti-inflammatory cytokines released in sepsis dramatically induce peripheral circulatory failure. However, blood pressure (BP) does not necessarily reflect the pathophysiology, due to compensated increase in cardiac output. In other words, even when BP is within the normal range, residual risk of circulatory failure induced by sepsis cannot be completely ruled out. It is therefore questionable whether BP is the most suitable non-invasive indicator to detect hemodynamic changes in sepsis.

Arterial stiffness is recognized as a clinical prognostic index and a potential therapeutic target in patients with atherosclerotic risk factors. Several studies have shown that increased arterial stiffness is associated with increased morbidity and mortality of cardiovascular disease (CVD). ${ }^{5}$ The cardio-ankle vascular index (CAVI) has been developed as an arterial stiffness index, which is derived from the $\beta$ theory with application of the Bramwell-Hill equation. ${ }^{6}$ The conspicuous feature of CAVI is independency from BP at the time of measurement. Furthermore, CAVI reflects the stiffness of the arterial tree from the origin of the aorta to the ankle, ${ }^{7}$ and has adequate reproducibility for clinical use. ${ }^{8,9}$ Furthermore, the increase in CAVI has also been reported to be associated with increased number of risk factors and severity of $\mathrm{CVD}^{10-12}$ and to be an independent predictor of major adverse cardiovascular events. ${ }^{13}$ These reports reveal that analyzing arterial stiffness based on CAVI may be helpful for identifying subjects with higher CVD risks.

Meanwhile, CAVI is useful not only for long-term management of atherosclerotic diseases, but also for evaluation of short-term hemodynamic changes. As for the relationship between CAVI and BP measurement, the independence of CAVI on measured BP has been confirmed experimentally in human subjects in vivo. Shirai et al ${ }^{14}$ demonstrated that administration of metoprolol, a selective $\beta 1$-blocker, did not change CAVI while the drug decreased $\mathrm{BP}$, whereas administration of doxazosin, a selective $\alpha 1$ blocker, induced decreases in both BP and CAVI. These data indicate that CAVI is mostly not affected by acute fluctuation in BP alone, but is affected by short-term arterial smooth muscle contraction. In other words, CAVI indicates not only organic stiffness but also functional stiffness. Additionally, Masugata et $\mathrm{al}^{15}$ reported that the increase in CAVI preceded the appearance of hypertension induced by sunitinib, a multi-targeted tyrosine kinase inhibitor. This report suggests that CAVI may detect hemodynamic instability that precedes change in BP.

In this study, using CAVI, we examined the change in arterial stiffness before and after sepsis treatment. Furthermore, we analyzed whether serum PCT level as a sepsis severity marker contributes to hemodynamic change in sepsis.

\section{Subjects And Methods Design}

The study protocol was prepared in accordance with the Declaration of Helsinki, and was approved by the institutional review board of Sakura Hospital, Toho University Medical Center (approval number: 2013-001). Before starting the study, we explained the purpose of the study to each subject and obtained written informed consent for participation in this study.

\section{Patient Recruitment}

Inclusion criteria of this study were American College of Chest Physicians/Society of Critical Care Medicine consensus definitions as the criteria for diagnosing SIRS and sepsis. ${ }^{16}$ Subjects with at least two of the following four clinical findings were considered as having sepsis in this study. Resultantly, 21 Japanese subjects with sepsis (14 males, 7 females, age $66.8 \pm 19.0$ years) were recruited in this study.

1) Body temperature higher than $38^{\circ} \mathrm{C}$ or lower than $36^{\circ} \mathrm{C}$,

2) Heart rate (HR) higher than $90 / \mathrm{min}$,

3) Respiratory rate higher than $20 / \mathrm{min}$ or arterial carbon dioxide tension $\left(\mathrm{PaCO}_{2}\right)$ lower than $32 \mathrm{mmHg}$,

4) White blood cell (WBC) count higher than $12,000 / \mu \mathrm{L}$ or lower than $4,000 / \mu \mathrm{L}$, or with $10 \%$ immature (band) forms.

In addition, a diagnosis of infectious disease was required by culturing a sample from the infected site or blood, according to the management guidelines for the diagnosis of infection in sepsis developed in $2003 .{ }^{17}$

Exclusion criteria were a previous history of CVD, other vascular diseases, definitive renal disease, or severe liver dysfunction. Subjects with ankle-brachial indices lower than 0.90 were also excluded because CAVI was apparently low in patients with severe arterial occlusive diseases. $^{7}$

Resuscitation protocols related to hemodynamic management and antibiotics administration were performed in accordance with Surviving Sepsis Campaign Guidelines 2012 (SSCG 2012) ${ }^{18}$ However, Japanese guideline was 
applied only for the use of immunoglobulin, recombinant thrombomodulin or antithrombin III. ${ }^{19}$

\section{Data Collection And Laboratory Assay Methods}

Height and body weight were measured, and body mass index (BMI) was calculated (weight in kilogram divided by square of height in meter). Venous blood samples were obtained in the emergency room at presentation and after 1-week of sepsis treatment, and complete blood count (CBC), C-reactive protein (CRP) and PCT were measured. $\mathrm{CBC}$ was performed by the electrical impedance method. C-reactive protein was quantified by latex-enhanced nephelometry. Serum PCT level, measured using the Elecsys BRAHMS PCT assay (Roche Diagnostics K.K, Swiss) based on the ELISA method, ${ }^{20}$ was also converted to logarithmic scale as $\ln (\mathrm{PCT})$ to curb departure from normality.

\section{Measurement Of CAVI And Blood Pressure}

CAVI was measured using the VaSera VS-1500 system (Fukuda Denshi Co Ltd, Tokyo, Japan). CAVI was obtained by measuring $\mathrm{BP}$ and pulse wave velocity (PWV) according to the following formula: CAVI $=\mathrm{a}\{(2 \rho / \Delta \mathrm{P}) \times \ln (\mathrm{Ps} / \mathrm{Pd})$ $\mathrm{PWV} 2\}+\mathrm{b}$, where Ps is systolic blood pressure; $\mathrm{Pd}$ is diastolic blood pressure; $\Delta \mathrm{P}$ is $\mathrm{Ps}-\mathrm{Pd} ; \rho$ is blood density, and a and $\mathrm{b}$ are constants.

Measurements of CAVI were performed at the following two time points: presentation at the emergency room and after 1-week of sepsis treatment. Cuffs were applied to bilateral upper arms and ankles, with the subject lying supine and the head held in midline position. After resting for $10 \mathrm{~min}$, the examinations were performed. To detect the brachial and ankle pulse waves with cuffs, a low cuff pressure from 30 to $50 \mathrm{mmHg}$ was used to minimize the effect of cuff pressure on hemodynamics. Thereafter, BP was measured from the cuff of the upper arm. PWV was obtained by dividing the vascular length by the time for which the pulse wave propagated from the aortic valve to the ankle, and was measured using cuffs at the upper arms and ankles. All the measurements and calculations were performed automatically. The details of CAVI and the measurement have been described previously. ${ }^{7}$

\section{Statistical Analysis}

All data are expressed as mean \pm standard deviation (SD). The SPSS 15.0 software (SPSS Inc., Chicago, Ill, USA) was used for statistical analyses. Paired $t$-test was performed to determine whether intragroup differences between presentation and after 1-week of treatment were statistically significant. Student's $t$-test or Fischer exact test was performed to determine whether subgroup differences were statistically significant. Pearson's rank correlation was used to verify the correlation between hemodynamic factors. In all comparisons, $P$ values less than 0.05 were considered statistically significant.

\section{Results}

\section{Patient Characteristics Before And After I-Week Of Sepsis Treatment}

We analyzed a total of 21 septic patients (14 males and 7 females, age $62.8 \pm 19.0$ years), and compared patient characteristics before and after 1-week of sepsis treatment, as shown in Table 1. Among 21 subjects, $33.3 \%$ had hypertension and $28.6 \%$ had diabetes. The average number of SIRS criteria met at presentation was $2.43 \pm 1.12$. All subjects received antibiotics including meropenem (33.3\%), ceftriaxone (42.9\%), sulbactam/ampicillin (14.3\%) and tazobactam/ piperacillin (9.5\%). In some patients, intravenous immunoglobulin $(33.3 \%)$, recombinant thrombomodulin $(23.8 \%)$ or antithrombin III (14.3\%) was administered. Ultimately, all subjects recovered from sepsis.

After 1-week sepsis treatment, significant increases in CAVI $(7.9 \pm 2.4$ to $9.6 \pm 1.8, P<0.001)$ and platelet (PIt) count were observed, while decreases in HR, WBC, CRP and $\ln (\mathrm{PCT})$ were also found. Significant changes in systolic and diastolic BP were not observed.

\section{Types And Proportions Of Infectious Diseases Diagnosed Among Participant}

Most of the patients (42.9\%) were diagnosed as having sepsis caused by pyelonephritis, and the other major underlying causes were pneumonia, lung abscess, hepatic abscess and cholecystitis. Iliopsoas abscess, spondylitis, vasculitis and cellulitis were less frequent causes (Table 2).

\section{Correlations Among Changes In Clinical Variables}

Correlations between hemodynamic variables or sepsis severity markers were verified in Table 3 . The change in CAVI was correlated positively with that in systolic BP (SBP) $(R=0.585, P=0.005)$, and negatively with that in $\ln (\mathrm{PCT})(R=-0.546, P=0.010)$. In addition, there were 
Table I Patient Characteristics Before And After I Week Of Sepsis Treatment

\begin{tabular}{|c|c|c|c|}
\hline & $\begin{array}{l}\text { At } \\
\text { Presentation }\end{array}$ & $\begin{array}{l}\text { After I } \\
\text { Week }\end{array}$ & $P$ \\
\hline $\mathrm{N}$ (male/female) & $21(14 / 7)$ & - & - \\
\hline Age (years) & $62.8 \pm 19.0$ & - & - \\
\hline Height $(\mathrm{cm})$ & $163.0 \pm 9.6$ & - & - \\
\hline Body weight (kg) & $64.2 \pm 17.9$ & - & - \\
\hline BMI $\left(\mathrm{kg} / \mathrm{m}^{2}\right)$ & $24.0 \pm 5.7$ & - & - \\
\hline CAVI & $7.9 \pm 2.4$ & $9.6 \pm 1.8$ & $<0.001$ \\
\hline $\mathrm{SBP}(\mathrm{mmHg})$ & $|2| \pm 30$ & $125 \pm 14$ & 0.523 \\
\hline $\mathrm{DBP}(\mathrm{mmHg})$ & $70 \pm 15$ & $70 \pm 12$ & 0.939 \\
\hline $\mathrm{HR}(/ \mathrm{min})$ & $101 \pm 16$ & $76 \pm 13$ & $<0.001$ \\
\hline WBC $(/ \mu \mathrm{L})$ & $17,104 \pm 7,579$ & $8,874 \pm 4,090$ & $<0.001$ \\
\hline Plt $(/ \mu \mathrm{L})$ & $22.7 \pm 11.5$ & $31.7 \pm 10.7$ & 0.001 \\
\hline CRP (mg/dL) & $20.9 \pm 8.8$ & $4.6 \pm 3.9$ & $<0.001$ \\
\hline PCT (ng/mL) & $44.2 \pm 102.9$ & $0.7 \pm 1.3$ & 0.064 \\
\hline $\ln (P C T)$ & $1.90 \pm 1.94$ & $0.39 \pm 0.46$ & $<0.001$ \\
\hline Hypertension (\%) & $7(33.3)$ & - & - \\
\hline $\begin{array}{l}\text { Diabetes mellitus } \\
(\%)\end{array}$ & $6(28.6)$ & - & - \\
\hline
\end{tabular}

Notes: Data are presented as mean \pm SD. Paired $t$-test was used to compare before and after I week of treatment.

Abbreviations: BMI, body mass index; CAVI, cardio-ankle vascular index; HR, heart rate; WBC, white blood cell; Plt, platelet; CRP, C-reactive protein; PCT; procalcitonin.

Table 2 Types And Proportions Of Infectious Diseases Diagnosed Among Participant

\begin{tabular}{|l|l|}
\hline Infectious Disease & Frequency (\%) \\
\hline Pyelonephritis & $9(42.9)$ \\
Pneumoniae, lung abscess & $4(19.0)$ \\
Hepatic abscess, cholecystitis & $4(19.0)$ \\
Iliopsoas abscess & $\mathrm{I}(4.8)$ \\
Spondylitis & $\mathrm{I}(4.8)$ \\
Vasculitis & $\mathrm{I}(4.8)$ \\
Cellulitis & $\mathrm{I}(4.8)$ \\
\hline
\end{tabular}

also significant correlation between the change in SBP and that in $\ln (\mathrm{PCT})(R=-0.611, P=0.003)$.

\section{Comparison Of Characteristics At Presentation And Changes In Parameters In Subjects With Higher Or Lower Pct \\ Level}

Additionally, we compared patients stratified by the severity of infectious disease. The subjects were divided into two groups by the cut-off PCT level for severe sepsis: ${ }^{21}$ PCT level at presentation $\geq 2.0 \mathrm{ng} / \mathrm{mL}$ and $<2.0 \mathrm{ng} / \mathrm{mL}$.
Subjects with PCT at presentation $\geq 2.0 \mathrm{ng} / \mathrm{mL}$ had significantly higher $\triangle \mathrm{CAVI}, \triangle \mathrm{Plt}$ count, $\mathrm{PCT}$ at presentation and lower $\triangle \mathrm{PCT}$ compared with $<2.0 \mathrm{ng} / \mathrm{mL}$. Furthermore, a notable but not significant increase in SBP was observed in subjects with PCT at presentation $\geq 2.0 \mathrm{ng} / \mathrm{mL}$. These results indicated that higher serum PCT level was associated with relatively larger amplitude of hemodynamic changes after treatment (Table 4).

\section{Changes In CAVI, SBP And HR Before And After I-Week Of Sepsis Treatment}

Figure 1 demonstrates the changes in CAVI, SBP and HR from before to after 1-week of sepsis treatment.

Only 4 of 21 subjects showed SBP below $90 \mathrm{mmHg}$ at presentation, which is the cut-off value of septic shock. ${ }^{22}$ Almost all (20 of 21) subjects, especially subjects with PCT at presentation $\geq 2.0 \mathrm{ng} / \mathrm{mL}(100 \%)$, showed an increase in CAVI ( $\triangle$ CAVI, $1.7 \pm 1.4 ; \Delta \%$ CAVI, $20.0 \pm 39.2 \%$ ) after treatment. On the other hand, the change in SBP was not uniform ( $\triangle \mathrm{SBP}, 4.1 \pm 29.2 \mathrm{mmHg} ; \Delta \% \mathrm{SBP}, 2.9 \pm 22.1 \%$ ). All subjects showed a decrease in HR after treatment, whereas a greater rate of change was observed in subjects with PCT at presentation $<2.0 \mathrm{ng} / \mathrm{mL}(-28.4 \pm 10.2$ vs $-18.9 \pm 11.2 \%$, $P=0.046)$.

There was no association between CAVI and SIRS score, prevalence of hypertension and diabetes, type of infectious disease or treatment.

\section{Discussion}

We analyzed 21 septic patients before and after 1-week of treatment. Analysis of all subjects showed an increase in CAVI after sepsis treatment but no significant change in BP. Besides, significant correlations were observed for all combinations among the change in CAVI, SBP and $\ln$ (PCT), respectively. Consequently, CAVI may reflect hemodynamic change in sepsis more sensitively than BP. Additionally, the increase in CAVI after treatment in subjects with PCT at presentation $\geq 2.0 \mathrm{ng} / \mathrm{mL}$ was greater than that in subjects with PCT $<2.0 \mathrm{ng} / \mathrm{mL}$. Serum levels of PCT have also been observed to increase with increasing severity of sepsis and organ dysfunction. ${ }^{23}$ Therefore, the present study may suggest that arterial stiffness is altered depending on sepsis severity. CAVI might decrease at acute phase of sepsis, and rise to original levels after treatment. However, we were not able to verify sepsisinduced decrease in CAVI at presentation, because most of the data before presentation were missing in this study. 
Table 3 Correlations Among Changes In Clinical Variables

\begin{tabular}{|c|c|c|c|c|c|c|c|c|c|}
\hline & $\Delta$ CAVI & $\Delta \mathrm{SBP}$ & $\Delta \mathrm{DBP}$ & $\Delta \mathrm{HR}$ & $\triangle W B C$ & $\Delta \mathbf{P I t}$ & $\Delta \mathrm{CRP}$ & $\triangle \mathrm{PCT}$ & $\Delta \ln (\mathrm{PCT})$ \\
\hline$\triangle \mathrm{CAVI}$ & & 0.585 & 0.182 & 0.301 & 0.300 & 0.233 & 0.023 & -0.369 & -0.546 \\
\hline$\triangle \mathrm{SBP}$ & 0.005 & & 0.522 & -0.201 & 0.013 & 0.096 & 0.061 & -0.278 & -0.611 \\
\hline$\triangle \mathrm{DBP}$ & 0.430 & 0.015 & & -0.520 & 0.112 & -0.123 & 0.227 & -0.101 & -0.276 \\
\hline$\Delta \mathrm{HR}$ & 0.185 & 0.383 & 0.016 & & 0.305 & 0.311 & -0.242 & -0.280 & -0.316 \\
\hline$\triangle \mathrm{WBC}$ & 0.187 & 0.956 & 0.628 & 0.179 & & 0.104 & 0.149 & 0.042 & 0.139 \\
\hline$\Delta \mathrm{Plt}$ & 0.310 & 0.680 & 0.595 & 0.170 & 0.654 & & -0.335 & -0.141 & -0.387 \\
\hline$\triangle \mathrm{CRP}$ & 0.922 & 0.791 & 0.323 & 0.291 & 0.519 & 0.138 & & 0.259 & 0.210 \\
\hline$\triangle \mathrm{PCT}$ & 0.100 & 0.222 & 0.664 & 0.219 & 0.856 & 0.541 & 0.256 & & 0.690 \\
\hline$\Delta \ln (\mathrm{PCT})$ & 0.010 & 0.003 & 0.227 & 0.163 & 0.549 & 0.083 & 0.361 & 0.001 & \\
\hline
\end{tabular}

Notes: Pearson's rank correlation matrix showing statistical relationships. Right side (above diagonal) shows correlations of the raw values; left side (below diagonal) shows $P$ values.

Abbreviations: CAVI, cardio-ankle vascular index; HR, heart rate; WBC, white blood cell; Plt, platelet; CRP; C-reactive protein; PCT; procalcitonin.

However, a 67-year-old man who presented with sepsis and cholecystitis underwent CAVI measurement before developing sepsis. His CAVI was 9.3 before sepsis, 7.6 at presentation and 9.9 after 1-week of sepsis treatment.

Several reports have revealed that hyperproduction of nitric oxide (NO) by the inducible form of NO synthase contributes to vascular collapse and septic shock. ${ }^{24}$ This pathophysiology is suspected to cause the decreased CAVI observed in septic patients at presentation. Incidentally, which is the type of artery mainly involved in decreased arterial stiffness caused by sepsis? There are three main types of arteries: elastic arteries that receive blood directly from the heart to the aorta and pulmonary artery, muscular arteries that distribute blood from elastic arteries to various parts of the body, and arterioles that deliver blood from muscular arteries to capillaries. For example, calcium channel blockers that reduce resistance in arterioles preferential to elastic and muscular arteries almost do not decrease CAVI. ${ }^{25,26}$ On the other hand, nitroglycerin (NTG) that liberates NO decreases CAVI probably through functionally

Table 4 Comparison Of Characteristics At Presentation And Changes In Parameters In Subjects With Higher Or Lower PCT Level

\begin{tabular}{|c|c|c|c|}
\hline & Subjects With PCT $\geq 2.0 \mathrm{ng} / \mathrm{mL}$ & Subjects With PCT $<2.0 \mathrm{ng} / \mathrm{mL}$ & $P$ \\
\hline$N$ (male/female) & $10(7 / 3)$ & II (7/4) & $1.000 *$ \\
\hline Age (years) & $62.0 \pm 19.8$ & $63.5 \pm 19.3$ & 0.858 \\
\hline BMI $\left(\mathrm{kg} / \mathrm{m}^{2}\right)$ & $24.6 \pm 4.2$ & $23.5 \pm 6.9$ & 0.667 \\
\hline CAVI & $7.0 \pm 2.5$ & $8.7 \pm 2.1$ & 0.098 \\
\hline$\triangle \mathrm{CAVI}$ & $2.4 \pm 1.6$ & $1.1 \pm 0.9$ & 0.037 \\
\hline $\mathrm{SBP}(\mathrm{mmHg})$ & $110 \pm 30$ & $13 \mid \pm 27$ & 0.103 \\
\hline$\triangle \mathrm{SBP}(\mathrm{mmHg})$ & $17 \pm 35$ & $-8 \pm 17$ & 0.051 \\
\hline $\mathrm{DBP}(\mathrm{mmHg})$ & $66 \pm 20$ & $73 \pm 7$ & 0.232 \\
\hline$\triangle \mathrm{DBP}(\mathrm{mmHg})$ & $4 \pm 24$ & $-3 \pm 6$ & 0.378 \\
\hline $\mathrm{HR}(/ \mathrm{min})$ & $97 \pm 15$ & $105 \pm 16$ & 0.218 \\
\hline$\Delta \mathrm{HR}(/ \min )$ & $-19 \pm 13$ & $-31 \pm 12$ & 0.048 \\
\hline WBC $(/ \mu \mathrm{L})$ & $15,929 \pm 5,604$ & $18,172 \pm 9,164$ & 0.512 \\
\hline$\Delta \mathrm{WBC}(/ \mu \mathrm{L})$ & $-8,699 \pm 5,901$ & $-7,7 \mid 4 \pm 5,505$ & 0.698 \\
\hline Plt $(/ \mu \mathrm{L})$ & $18.8 \pm 9.6$ & $26.4 \pm 12.3$ & 0.133 \\
\hline$\Delta \mathrm{Plt}(/ \mu \mathrm{L})$ & $14.3 \pm 12.0$ & $4.2 \pm 8.1$ & 0.035 \\
\hline CRP (mg/dL) & $22.8 \pm 8.6$ & $19.2 \pm 9.0$ & 0.356 \\
\hline$\Delta \mathrm{CRP}(\mathrm{mg} / \mathrm{dL})$ & $-17.4 \pm 7.3$ & $-15.4 \pm 7.9$ & 0.558 \\
\hline РCT (ng/mL) & $92.2 \pm 136.5$ & $0.5 \pm 0.5$ & 0.038 \\
\hline $\ln (P C T)$ & $3.56 \pm 1.55$ & $0.39 \pm 0.30$ & $<0.001$ \\
\hline$\triangle \mathrm{PCT}(\mathrm{ng} / \mathrm{mL})$ & $-90.9 \pm 134.8$ & $-0.3 \pm 0.7$ & 0.038 \\
\hline$\Delta \ln (\mathrm{PCT})$ & $-2.92 \pm 1.18$ & $-0.23 \pm 0.40$ & $<0.001$ \\
\hline
\end{tabular}

Notes: Data are presented as mean \pm SD. Student's $t$-test and *Fischer exact test are used to compare subjects with or without PCT $\geq 2.0 \mathrm{ng} / \mathrm{mL}$.

Abbreviations: BMI, body mass index; CAVI, cardio-ankle vascular index; HR, heart rate; WBC, white blood cell; Plt, platelet; CRP; C-reactive protein; PCT; procalcitonin. 

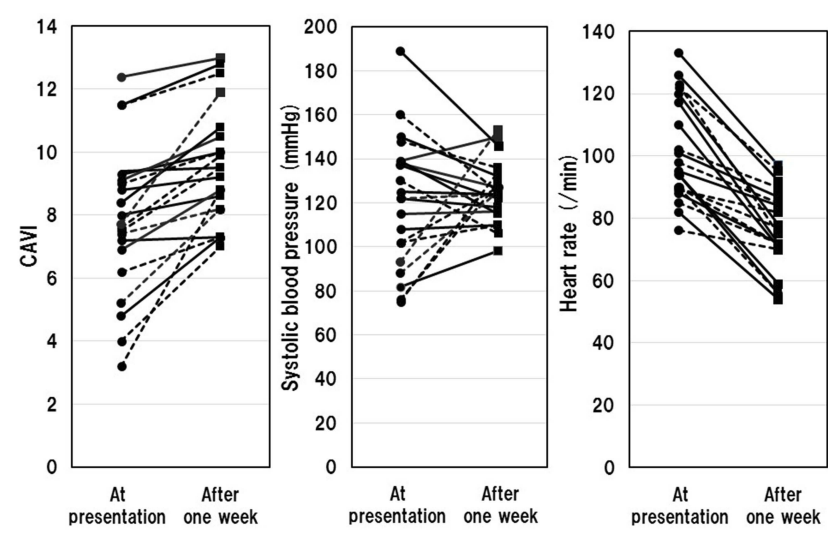

- : Subjects with PCT $<2.0 \mathrm{ng} / \mathrm{ml}$ Subjects with $\mathrm{PCT} \geq 2.0 \mathrm{ng} / \mathrm{ml}$

Figure I Changes in CAVI, SBP and HR before and after I week of sepsis treatment.

Notes: CAVI, SBP or HR for each participant at presentation (circles) and after I week of treatment (squares); Continuous lines indicate subjects with serum PCT $<2.0 \mathrm{ng} / \mathrm{mL}$ $(\mathrm{N}=\mathrm{II})$, and dotted lines indicate those with $\mathrm{PCT} \geq 2.0 \mathrm{ng} / \mathrm{mL}(\mathrm{N}=10)$.

Abbreviations: $\mathrm{CAVI}$, cardio-ankle vascular index; HR, heart rate.

reducing arterial stiffness from the aorta to the ankle. ${ }^{26,27} \mathrm{In}$ addition, Yamamoto et $\mathrm{al}^{28}$ have reported that NTG-induced decrease in CAVI depends on relaxation of both elastic and muscular arteries especially in healthy young subjects (age $30.9 \pm 3.9$ years), whereas elastic arterial stiffness scarcely decreases after NTG administration in elderly subjects with arteriosclerosis (age $72 \pm 6.4$ years). These findings may indicate that sepsis reduces CAVI through NO-mediated vasodilation, which occurs mainly in muscular arteries, and partially in elastic arteries in young persons.

On the other hand, chronic inflammatory diseases are known to contribute to increased arterial stiffness involved in premature atherosclerosis. ${ }^{29}$ For example, chronic inflammation based on visceral adiposity such as diabetes, hypertension and metabolic dyslipidemia is associated with high CAVI. ${ }^{30,31}$ Furthermore, the same is true of chronic inflammation associated with malignant tumors. ${ }^{32}$ Besides, CAVI can be reduced by proper anti-inflammatory approaches. ${ }^{33,34}$ These reports therefore appear to contradict our conclusion of the present study. However, sepsis-induced transient decrease in CAVI observed at presentation of our patients should not be expected to contribute to reduction of future vascular events. Transiently decreased CAVI in acute inflammation accompanied by hypercytokinemia may imply pathological vasodilation responses, but not anti-atherosclerotic action to resolve the chronic inflammation of blood vessel wall.

Interestingly, analysis of all subjects in the present study showed no significant BP change during sepsis treatment, whereas CAVI increased significantly. These findings suggest that even when arterial stiffness is reduced by sepsis, BP can be maintained as long as cardiac compensation is effective. Measuring CAVI of a septic patient in the emergency room therefore seems to be helpful to evaluate the risk of circulation crisis. Furthermore, for septic patients with markedly decreased CAVI, starting vasoconstrictor agents may be effective to prevent circulation failure even if they are not yet in a hypotensive state. In addition, an interpretable machine learning model for accurate prediction of sepsis has been reported recently. ${ }^{35}$ This amazing finding suggests that BP variabilities may be useful for realtime prediction of sepsis onset in applying artificial intelligence. In the future, the algorithm to predict the onset of sepsis may be constructed by combining CAVI and artificial intelligence.

If, instead of CAVI, PWV was used as an arterial stiffness marker, then we would not have obtained definitive results. There are many methods for measuring PWV, such as carotid-femoral $\mathrm{PWV}^{36}$ heart-to-femoral $\mathrm{PWV}^{37}$ and brachialankle PWV. ${ }^{38}$ However, PWV is known to depend strongly on BP at the time of measurement. Therefore, the validity of PWV in reflecting actual arterial stiffness is controversial, and this parameter is unsuitable for evaluating the vascular alteration in sepsis. Furthermore, carotid-femoral PWV has already been reported to have no association with sepsis severity and prognosis. ${ }^{39}$

However, our study has several limitations. First, the protocol in the present study was conducted on the assumption of 1 week after sepsis treatment as the recovery phase, whereas that might not always be certain. Furthermore, another problem was the lack of data to link hemodynamic variables such as cardiac output and systemic vascular resistance during the initial resuscitation phase of sepsis. Next, the sample size was relatively small. There were almost no pre-CAVI values for study participants. Finally, although the sepsis criteria were revised after the start of this study, the old criteria had to be used in compliance with the protocol. From these viewpoints, a large-scale prospective multicenter cohort study using the latest criteria is necessary.

\section{Conclusion}

In summary, CAVI may reflect sepsis-induced vascular alteration not indicated by BP change and is associated with sepsis severity. These findings suggest the usefulness of CAVI for managing circulatory failure in septic patients. 


\section{Acknowledgment}

We would like to thank all the investigators who participated in the study.

\section{Author Contributions}

All authors made substantial contributions to conception and design, acquisition of data, or analysis and interpretation of data; took part in drafting the article or revising it critically for important intellectual content; gave final approval of the version to be published; and agree to be accountable for all aspects of the work.

\section{Disclosure}

The authors report no conflicts of interest in this work.

\section{References}

1. Nyström PO. The systemic inflammatory response syndrome: definitions and aetiology. J Antimicrob Chemother. 1998;41(Suppl A):1-7. doi:10.1093/jac/41.suppl_1.1

2. Prkno A, Wacker C, Brunkhorst FM, Schlattmann P. Procalcitoninguided therapy in intensive care unit patients with severe sepsis and septic shock- a systematic review and meta-analysis. Crit Care. 2013;17(6):R291. doi:10.1186/cc12734

3. Levi M, van der Poll T. A short contemporary history of disseminated intravascular coagulation. Semin Thromb Hemost. 2014;40:874-880. doi:10.1055/s-0034-1395155

4. Singer M, Deutschman CS, Seymour CW, et al. The third international consensus definitions for sepsis and septic shock (sepsis-3). JAMA. 2016;315:801-810. doi:10.1001/jama.2016.0287

5. Satoh-Asahara N, Kotani K, Yamakage H, et al. Cardio-ankle vascular index predicts for the incidence of cardiovascular events in obese patients: a multicenter prospective cohort study (Japan Obesity and Metabolic Syndrome Study: JOMS). Atherosclerosis. 2015;242 (2):461-468. doi:10.1016/j.atherosclerosis.2015.08.003

6. Hayashi K, Handa H, Nagasawa S, Okumura A, Moritake K Stiffness and elastic behavior of human intracranial and extracranial arteries. J Biomech. 1980;13(2):175-184. doi:10.1016/0021-9290(80) 90191-8

7. Shirai K, Utino J, Otsuka K, Takata M. A novel blood pressureindependent arterial wall stiffness parameter; cardioankle vascular index (CAVI). J Atheroscler Thromb. 2006;13(2):101-107. doi:10. 5551/jat.13.101

8. Matsui Y, Kario K, Ishikawa J, Eguchi K, Hoshide S, Shimada K. Reproducibility of arterial stiffness indices (pulse wave velocity and augmentation index) simultaneously assessed by automated pulse wave analysis and their associated risk factors in essential hypertensive patients. Hypertens Res. 2004;27(11):851-857.

9. Kubozono T, Miyata M, Ueyama K, et al. Clinical significance and reproducibility of new arterial distensibility index. Circ J. 2007;71 (1):89-94. doi:10.1253/circj.71.89

10. Nakamura K, Iizuka T, Takahashi M, et al. Association between cardioankle vascular index and serum cystatin C levels in patients with cardiovascular risk factor. $J$ Atheroscler Thromb. 2009;16 (4):371-379. doi:10.5551/jat.no687

11. Miyoshi T, Doi M, Hirohata S, et al. Cardio-ankle vascular index is independently associated with the severity of coronary atherosclerosis and left ventricular function in patients with ischemic heart disease. J Atheroscler Thromb. 2010;17(3):249-258. doi:10.5551/jat. 1636
12. Nagayama D, Yamaguchi T, Saiki A, et al. High serum uric acid is associated with increased cardio-ankle vascular index (CAVI) in healthy Japanese subjects: a cross-sectional study. Atherosclerosis. 2015;239(1):163-168. doi:10.1016/j.atherosclerosis.2015.01.011

13. Sato Y, Nagayama D, Saiki A, et al. Cardio-ankle vascular index is independently associated with future cardiovascular events in outpatients with metabolic disorders. J Atheroscler Thromb. 2016;23 (5):596-605. doi:10.5551/jat.31385

14. Shirai K, Hiruta N, Song M, et al. Cardio-ankle vascular index (CAVI) as a novel indicator of arterial stiffness: theory, evidence and perspectives. J Atheroscler Thromb. 2011;18:924-938. doi:10.5551/jat.7716

15. Masugata $\mathrm{H}$, Senda S, Himoto T, et al. Early detection of hypertension in a patient treated with sunitinib by measuring cardio-ankle vascular index. Tohoku J Exp Med. 2009;218(2):115-119. doi:10.1620/tjem.218.115

16. American College of Chest Physicians/Society of Critical Care Medicine Consensus Conference. Definitions for sepsis and organ failure and guidelines for the use of innovative therapies in sepsis. Crit Care Med. 1992;20:864-874.

17. Cohen J, Brun-Buisson C, Torres A, Jorgensen J. Diagnosis of infection in sepsis: an evidence-based review. Crit Care Med. 2004;32(11 Suppl): S466-S494. doi:10.1097/01.ccm.0000145917.89975.f5

18. Dellinger RP, Levy MM, Rhodes A, et al. Surviving sepsis campaign: international guidelines for management of severe sepsis and septic shock: 2012. Crit Care Med. 2013;41(2):580-637. doi:10.1097/ CCM.0b013e31827e83af

19. Oda S, Aibiki M, Ikeda T, et al. Sepsis Registry Committee of the Japanese Society of Intensive Care Medicine. The Japanese Guidelines for the Management of Sepsis. J Intensive Care. 2014;2(1):55.

20. Müller B, Becker KL. Procalcitonin: how a hormone became a marker and mediator of sepsis. Swiss Med Wkly. 2001;131(4142):595-602. 2001/41/smw-09751

21. Seymour CW, Liu VX, Iwashyna TJ, et al. Assessment of clinical criteria for sepsis: for the Third International Consensus Definitions for Sepsis and Septic Shock (Sepsis-3). JAMA. 2016;315:762-774. doi:10.1001/jama.2016.0288

22. Levy MM, Fink MP, Marshall JC, et al. 2001 SCCM/ESICM/ACCP/ ATS/SIS International Sepsis Definitions Conference. Crit Care Med. 2003;31:1250-1256. doi:10.1097/01.CCM.0000050454.01978.3B

23. Giamarellos-Bourboulis EJ, Mega A, Grecka P, et al. Procalcitonin: a marker to clearly differentiate systemic inflammatory response syndrome and sepsis in the critically ill patient? Intensive Care Med. 2002;28:1351-1356. doi:10.1007/s00134-002-1398-z

24. Kirkebøen KA, Strand OA. The role of nitric oxide in sepsis-an overview. Acta Anaesthesiol Scand. 1999;43(3):275-288. doi:10.1034/j.1399-65 76.1999.430307.x

25. Miyashita Y, Saiki A, Endo K, et al. Effects of olmesartan, an angiotensin II receptor blocker, and amlodipine, a calcium channel blocker, on Cardio-Ankle Vascular Index (CAVI) in type 2 diabetic patients with hypertension. $J$ Atheroscler Thromb. 2009;16(5):621626. doi: $10.5551 /$ jat. 497

26. Chiba T, Yamanaka M, Takagi S, et al. Cardio-ankle vascular index (CAVI) differentiates pharmacological properties of vasodilators nicardipine and nitroglycerin in anesthetized rabbits. J Pharmacol Sci. 2015;128(4):185-192. doi:10.1016/j.jphs.2015.07.002

27. Shimizu K, Yamamoto T, Takahashi M, Sato S, Noike H, Shirai K. Effect of nitroglycerin administration on cardio-ankle vascular index. Vasc Health Risk Manag. 2016;12:313-319. doi:10.2147/VHRM.S106542

28. Yamamoto T, Shimizu K, Takahashi M, Tatsuno I, Shirai K. The effect of nitroglycerin on arterial stiffness of the aorta and the femoral-tibial arteries. J Atheroscler Thromb. 2017;24(10):10481057. doi: $10.5551 /$ jat.38646

29. Masugata H, Senda S, Himoto T, et al. Detection of increased arterial stiffness in a patient with early stage of large vessel vasculitis by measuring cardio-ankle vascular index. Tohoku J Exp Med. 2009;219 (2):101-105. doi:10.1620/tjem.219.101 
30. Satoh N, Shimatsu A, Kato Y, et al. Evaluation of the cardio-ankle vascular index, a new indicator of arterial stiffness independent of blood pressure, in obesity and metabolic syndrome. Hypertens Res. 2008;31(10):1921-1930. doi:10.1291/hypres.31.1921

31. Nagayama D, Watanabe Y, Saiki S, Shirai K, Tatsuno I. Lipid parameters are independently associated with Cardio-Ankle Vascular Index (CAVI) in healthy Japanese subjects. J Atheroscler Thromb. 2018;25(7):621-633. doi:10.5551/jat.42291

32. Shimizu N, Ban N, Watanabe Y, et al. The elevation of cardio-ankle vascular index in a patient with malignant lymphoma treated with a combination therapy of rituximab and cyclophosphamide, doxorubicin, vincristine, and prednisolone. J Clin Med Res. 2017;9(8):729732. doi:10.14740/jocmr3071w

33. Nagayama D, Saiki A, Endo K, et al. Improvement of cardio-ankle vascular index by glimepiride in type 2 diabetic patients. Int J Clin Pract. 2010;64(13):1796-1801. doi:10.1111/j.1742-1241.2010.02399.x

34. Masugata H, Senda S, Dobashi H, et al. Cardio-ankle vascular index for evaluating immunosuppressive therapy in a patient with aortitis syndrome. Tohoku J Exp Med. 2010;222(1):77-81. doi:10.1620/ tjem.222.77
35. Nemati S, Holder A, Razmi F, Stanley MD, Clifford GD, Buchman TG. An interpretable machine learning model for accurate prediction of sepsis in the ICU. Crit Care Med. 2018;46(4):547-553. doi:10.1097/CCM.0000000000002936

36. O'Rourke MF, Staessen JA, Vlachopoulos C, Duprez D, Plante GE. Clinical applications of arterial stiffness; definitions and reference values. Am J Hypertens. 2002;15:426-444. doi:10.1016/s0895-7061 (01)02319-6

37. Hasegawa M. Fundamental research on human aortic pulse wave velocity. Jikei Med J. 1970;85:742-760.

38. Yamashina A, Tomiyama H, Takeda K, et al. Validity, reproducibility, and clinical significance of noninvasive brachial-ankle pulse wave velocity measurement. Hypertens Res. 2002;25(3):359-364.

39. Kazune S, Grabovskis A, Cescon C, Strike E, Vanags I. Association between increased arterial stiffness and clinical outcomes in patients with early sepsis: a prospective observational cohort study. Intensive Care Med Exp. 2019;7(1):26. doi:10.1186/s40635-019-0256-z
Vascular Health and Risk Management

\section{Publish your work in this journal}

Vascular Health and Risk Management is an international, peerreviewed journal of therapeutics and risk management, focusing on concise rapid reporting of clinical studies on the processes involved in the maintenance of vascular health; the monitoring, prevention and treatment of vascular disease and its sequelae; and the involvement of metabolic disorders, particularly diabetes. This journal is indexed on PubMed Central and MedLine. The manuscript management system is completely online and includes a very quick and fair peerreview system, which is all easy to use. Visit http://www.dovepress. com/testimonials.php to read real quotes from published authors. 